\title{
That sinking feeling
}

Y ou are doing a breast reduction. You have chosen a vertical flap and inverted $\mathrm{T}$ incision. You like the vertical reduction and medial pedicle because there is a shorter incision, but you think there will be too much skin excess, so it will be better to excise it now. For some reason, every time you do the inferior pedicle the base of the pedicle becomes thin and narrow. This worries you. You see in your mind's eye the nipple-areola complex turning blue and edematous and tomorrow having to make a decision about what to do: remove the sutures or convert the areola to a free graft. You dislike free grafted areolae. You have performed some, and the areolae become too flat and shiny, and the nipple projection fades back. Other plastic surgeons tell you free nipple grafts look good but you are unconvinced.

You measured the pedicle at $15 \mathrm{~cm}$ before surgery. You measure it now and it is $20 \mathrm{~cm}$ in length. It is narrow and thin at the base even though you tried to make it thicker this time for better circulation. You begin to suture the breast together, and you like the new appearance. The operating room nurses like it too.

You can't tell much about the areola circulation because the patient has dark skin, so you can't tell if it is pink or blue. You wish you could feel if the areola was warm but you can't tell through your gloves. You wish you had done a vertical bipedicle reduction, because there might have been better blood supply, and a dermal base to free graft on if there is poor circulation tomorrow.

You get that sinking feeling. You hope you chose the best pedicle. Too late now to change your mind.

You start the opposite side, and keep checking the first side, keeping your tone light, covering your anxiety.

You wish you had done a medial pedicle. The flap would have been shorter, with better blood supply, but you have seen the areola become oval and pulled in. You wish you had done a superior pedicle but you did not like the idea of the pedicle being twisted inside your closure. You recall the expert who said his 1500 vertical reductions had no areola losses. So, there should be no reason to see the patient the next day to check the circulation.

You finish. The appearance is good, but you can't tell much more about the

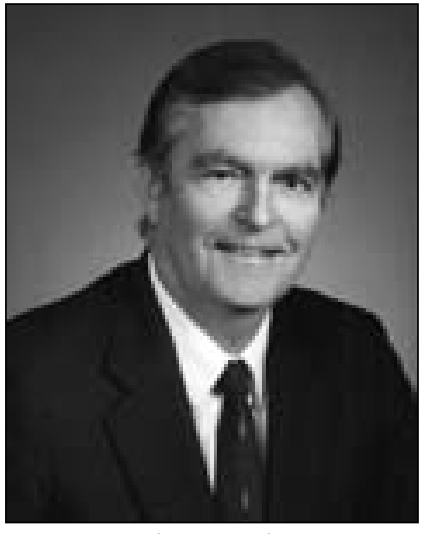

John R Taylor circulation than you could before. You make sure the dressing is not too tight. At least the bleeding was easy to control and you hope the patient will not get a hematoma.

You see her again the next morning. You have asked her to come with nothing to eat or drink, to be prepared in case you have to take her back to the operating room. Everything is good. The areolae are warm to touch, there is no hematoma, and she loves her new shape and size. No sinking feeling now.

You realize that you like the feeling in small doses. You wonder if you can think of any other way to align the pedicle, a way no one has thought of before. You decide next time you will do a medial pedicle, and maybe combine it with a short, inverted $\mathrm{T}$ incision.

Maybe the feeling is what makes you try new operations?

Maybe it is not so bad after all.

John R Taylor 